\title{
THE ROLE OF UTILITY COMPANIES IN MUNICIPAL PLANNING OF SMART ENERGY COMMUNITIES
}

\author{
BRITA FLADVAD NIELSEN, EIRIK RESCH \& INGER ANDRESEN \\ Department of Architecture and Planning, NTNU, Norway.
}

\begin{abstract}
Bergen and Oslo municipalities focus on integrating energy concerns into city planning and regard this as an opportunity to further lower greenhouse gas emissions. Due to a lack of tools and clear definitions of what Smart Energy Communities (SECs) are and how planning should be done in order to affect the overarching emission reduction goals, utility companies end up taking a leading role as advisors and influence definitions and strategies in the final design. Based on two case studies of SEC projects in Norway, the authors highlight the need for increased work to create feasible and understandable definitions and strategies for the planning of SECs. In our case studies, city planners struggle to include energy aspects in the early planning phase and to align their objectives of citizen well-being and reduced private car dependency with energy concerns. At the same time, utility companies respond to the perceived threat of more self-sufficient communities by depicting a role closer to the end-user and by offering a pragmatic cost/benefit view on the planning of energy supply options.

Keywords: Energy planning, Integrated energy planning, Smart Energy Communities, Sustainable urban planning, Zero Emission Neighbourhoods
\end{abstract}

\section{INTRODUCTION}

This work is part of an ongoing national research project entitled Planning Instruments for Smart Energy Communities (PI-SEC) that aims to deliver efficient planning instruments for integrated energy design at the neighbourhood scale, qualified for Norwegian planning context in cooperation with public stakeholders.

Smart Energy Communities (SEC) and Zero Emission Neigbourhoods (ZEN) have no agreed upon definitions. For buildings, researchers have attempted to define zero or near zero emission/energy levels [1-3] based on different cases and target achievement in different countries. Finding a common ground on what defines zero emission communities and neighbourhoods becomes even more challenging. The complexity of this question, together with the current efforts to integrate energy aspects into urban planning, means that multiple stakeholders, including utility companies, private developers, municipal planners, and politicians have the opportunity to influence the definitions of SEC and ZEN when planning new communities and neighbourhoods. Our working definition of SEC is 'an area of buildings; infrastructure and citizens sharing planned societal services, where environmental targets are reached through integration of energy aspects into planning and implementation. The Smart Energy Community aims to become highly energy efficient and increasingly powered by renewable and local energy sources and lowered dependency on fossil fuels. The spatial planning and localization of the SEC targets reduction of carbon emissions through the relationship with the larger region, both through the design of energy systems and by including sustainable mobility aspects of the larger region. It further encourages sustainable behaviour through its overall design from building and citizen scale to community scale'. Societal services is here meant as in the sequence of order common in Norway's planning and building act; such as energy delivery, transportation and road network, health and social services, kindergartens, play areas, and schools.

Norway has committed to ambitious targets for reduction of greenhouse gas emissions (https://www.regjeringen.no/en/topics/climate-and-environment/climate/ 
innsiktsartikler-klima/agreement-on-climate-policy/id2076645/). Two municipalities, Bergen and Oslo, have taken lead roles in reducing their greenhouse gas emissions. Bergen has stated that they will be 'Norway's greenest city' by becoming a '1.5-degree city [4]', while Oslo aims to reduce emissions by 50\% within 2020 and $95 \%$ within 2020 compared to 1990 levels [5].

In the presented study, we analyse and compare the planning of two Norwegian SECs through interview analyses. The planning of Zero Village Bergen (ZVB) and Furuset Forbildeprosjekt materialize Oslo and Bergen municipalities' ambitions to integrate energy into spatial planning. ZVB is a planned and designed development project, which is to include approximately 800 new dwellings, a kindergarten, and some commercial buildings in an uninhabited area north of the city of Bergen. This project is ready to be implemented yet still awaiting final political approval. Furuset Forbildeprosjekt is a re-development project to be integrated into an existing neighbourhood within the city of Oslo. It includes 2500 planned new dwellings in the city area and aims to create 1500 new workplaces. Parts of the plan have been implemented; including a park to improve the social aspects of the area.

The challenges of cross-disciplinary tasks such as the integration of energy into urban planning are described as being wide reaching and complex. This is explained in literature on utility management describing political challenges and stakeholder collaboration $[8,9]$. Historically, we know that the Norwegian energy sector has been closely related to the political level of building policy because the energy sector has been governed by the state. The energy sector in Norway was state run but underwent the same liberalization of utilities as elsewhere in Europe during the 90s $[10,11]$. There are some studies describing the influence of liberalization on urban governance and energy planning [12-14]. These studies describe that municipalities went from having a clear decision-making role in energy planning to having a negotiation role seeking to involve utilities in their planning processes. After liberalization took place, municipalities had to invest more time and effort into collaboration, which means that they have a need for negotiation skills and suitable collaboration methods. We assume that Norwegian municipalities currently find themselves in this negotiating role with utility companies, as we see that the municipalities attempt to integrate energy aspects into urban planning.

Based on a study of two Smart Energy Community cases we want to add to the described literature and to the emerging knowledge on the integration of energy in urban planning by investigating the role of utility companies in the planning of SECs. By integrated energy planning we mean 'an approach to find environmentally friendly, institutionally sound, socially acceptable and cost-effective solutions of the best mix of energy supply and demand options for a defined area to support long-term regional sustainable development. It is a transparent and participatory planning process, an opportunity for planners to present complex, uncertain issues in a structured, holistic and transparent way, for interested parties to review, understand and support the planning decisions' [16].

During our analysis of interviews with city planners, climate sections in the municipalities of Oslo and Bergen, and with representatives of the involved utility companies, we found that the issue of energy competency within the municipalities composes a significant challenge when moving towards integrated energy planning. Within this paper, we seek to discuss and answer the following three research questions:

a. What is the utility companies' role in shaping definitions and strategies in the planning of SEC (based on the two case studies)?

b. How do utility companies see their future role in integrated urban energy planning?

c. Which measures may be taken within municipal planning of SECs to help manage the identified challenges and opportunities? 


\section{METHODOLOGY}

Between June and October 2016, we conducted 15 semi-structured interviews with involved stakeholder participants in two Smart Energy Community (SEC) projects in Oslo and Bergen respectively. Four interviews were conducted with utility companies, six with municipal planners, three with researchers from NTNU and Christian Michelsen Research, one with the coordinating organization Futurebuilt, and one with an architectural company central to the ZVB project. FutureBuilt is a ten-year programme (2010-2020) with a vision of developing carbon neutral urban areas and high-quality architecture. The interviews were done in person and lasted between 45 and 60 minutes. The interviews focused on taking a narrative approach combined with graphic elicitation [17, 18]. A narrative approach means that the interviewer seeks to achieve a chronological account from the participants' perspective of something. In this case, we wanted to understand each participants' experience of the planning process of these SECs. The graphic elicitation [17, 18] part implied that we asked the participants to draw a diagram, which represented a timeline of the planning process. During the drawing exercise, we asked the participants to think aloud and explain which factors had influenced the process and the outcome. This method improves the understanding between the interviewer and the interviewee, and assists the communication process. Participants were selected following a selective snowball approach [19]. This means that we had a primary sampling requirement that the participants needed to have been involved in the SEC planning; next, that it was a chain of referral that guided the sampling. We started with the project leader who had the most information about the entirety of the planning timeline and then interviewed participants following suggestions from the first participant. This approach made it possible for us to compare the different views by their explanation of the timeline and which challenges and solutions had occurred, as well as insights into who and what were keys to solving the said challenges. Following this task, we asked how the participants defined Smart Energy Communities (SEC) and Zero Emission Neighbourhoods (ZEN), and which challenges they regarded as contextual challenges of the planning of the two cases. By contextual we mean site-specific, but we also explained that we were interested in views on regional or national characteristics that might make SEC planning different compared to other countries. We transcribed the interviews verbatim and analysed them to find meaning bearers that could provide insights into how participants define SEC and ZEN, as well as what are the challenges to achieve these goals/visions, and what is the current and future role of the utility companies

\section{FINDINGS}

We present our findings in the same sequence as the three research questions.

3.1 What is the utility companies' role in shaping definitions and strategies in SEC development (based on the two case studies)?

As explained in the methodology section, we asked the involved stakeholders in each project to draw a timeline indicating the different steps of the planning process. They explained when and why different stakeholders were involved as well as the main challenges and strategies. We learned that the major utility companies had come on board about 2/3rds into the planning process in both projects, after the sites had been selected and the zoning plan had been designed. Once the utility companies were onboard, however, it seems as if their influence on the project quickly increased, as the projects were getting closer to implementation and into the implementation phase. It is not clear-cut to say which parts of the timeline should be 
defined as "planning" or when it transitions to 'implementation', yet we still perceive both of the projects to be in the late planning phase as they are still awaiting political approval and are discussing relevant design issues. In the Oslo case, the planning process involved mainly city planners in dialogue with citizens and included urban design competitions to meet expectations of citizens. In the ZVB case, the early planning involved researchers from NTNU and CMI, the architectural office Snøhetta and the energy consultant Multiconsult, together with the private developer. The two projects have well-defined goals in terms of emission reduction. Yet, it appeared that the utility companies viewed the projects in relation to their overall market approach within the concession area and therefore it seems as if the utility companies have a rather pragmatic view on the issue of smart energy community design. There had not been any discussion amongst stakeholders on system boundaries for the energy integration into the SEC planning, yet the view of the utility companies seems to be that SECs are a sort of 'off-grid systems', which aims at self-sufficiency. Utility companies regard this concept as impractical.

'On the thermal side, you can attach district heating to the smart energy community. But you can also scale down district heating so that you have a low-temperature grid inside the community, and that you build it for energy... future energy efficient buildings. So we can see that you can be attached to the larger system, but you can also design the community so that it initially looks like an island... However... we are influenced by our work and... I do not believe in 100\% off-grid solutions'

\section{Representative of Utility company \\ (translated from Norwegian by authors)}

The interviewed participants from utility companies emphasized this view further when we asked them to define the concepts SEC and ZEN. They regard SECs as 'islands' in terms of energy use and that they should be calculated as such. When asked how they define ZEN, they see it as broader than SECs.

'Zero emission neighbourhoods should include everything, down to what people are having for breakfast'

\section{Representative of Utility company \\ (translated from Norwegian by authors)}

When discussing these topics further, it became clear that the utility companies approached the two concepts SEC and ZEN as two competing ideals during the planning. SECs, on one hand, being 'utopia' in the sense that the utility companies do not commit to the idea that any Norwegian community should be 'off-grid' or planned independently; and ZEN, which they also perceive as impractical because it attempts to be too all-encompassing. The utility companies pragmatically seek something in between, and they exemplify this by calling for the cost/benefit view to be better included in institutional and governmental integration scenarios. They hence take an advisory role and see themselves as translators between the ideal and the feasible. This advisory role includes meeting general ideas of what meaningful resource use means to city planners, with suggestions that match the objectives of the city planners. For example, within the Oslo case, the urban planners seem to have the common view that 'it is good to use what you have' and that energy production locally should be visible locally to citizens, and this view is met by utility companies' suggestions to include electric buses and to include visualization strategies to show energy use publicly to citizens. 
'I believe that it is a good thing, to use optimally the energy that we have available, and that the citizens of Furuset should have ownership of the energy produced in the area'

City planner (translated from Norwegian by authors)

The advisory role of utility companies increases once the project approaches implementation stage. City planners and interviewees in the climate sections explain that the increased advisory role of one utility company in the projects is a result of two main issues:

- The complexity of breaking down emission goals to project level actions: The municipality finds it difficult to break down emission goals to building project level actions. Instead, other priorities overrun the environmental goals. For example, the need for a higher number of dwellings in Furuset and the priorities of the National Road Administration are misaligned with the environmental goals of Furuset, while the in ZVB case, the localization of the project is misaligned with the densification policy of Bergen. Further, there are no legal requirements in which municipalities can enforce higher environmental standards for buildings or a community beyond the technical standards. As a result, they explain that they witness that the overall emission reduction objective loses priority along the project timeline. They explain that this tendency to lose track of the target during the process, combined with the lack of competency that they experience regarding energy within the municipality, results in a strong dependency on the utility companies, who are the traditionally main advisers to energy policy within the municipalities.

- Fear of increased workload and added complexity: The inability to include energy from the early planning stage due to lack of incentives for utility companies, 'tradition' and misaligned mandates are listed as reasons for not integrating energy earlier on. Utility companies do not see why they should be included in start-up meetings between private builders and municipality. They currently do not see which incentives they have for being there before the project has been approved. Moreover, participants in the climate sections within the municipalities explain that if they ask for utilities to be included in start-up meetings, climate section staff explain that city planners and private developers are reluctant to include utility companies because they think more stakeholders will believe that the two SEC planning processes already are lengthy. They would like to see measures that can speed it up rather than add extra work through an increased number of stakeholders. In addition, city planners perceive their mandate to be the creation of good socio-economic communities, and that energy is not their main concern. It becomes difficult to prioritize energy integration and to work on energy scenarios extensively when the municipalities already feel unable to achieve the communities that they want due to the difficulties of stakeholder agreement and misalignment of public and private interests in the spatial planning. Because of this complexity, they rely on the utility company to influence the final energy design instead of intentionally managing it.

\subsection{How do utility companies see their future role in integrated urban energy planning?}

The utility companies express that the idea of a self-sufficient community per se is a threat to the current conventional business model of the major utilities in Norway. At the same time, they see that a ZEN way of thinking, in the way that they define it themselves, is an opportunity. They include the end-user aspect and end-user behaviour as part of the ZEN image; they regard the ZEN concept as a smart technology related opportunity where they can involve the 
end user more into energy choices. Several statements during the interviews indicate that they regard 'smartness' in terms of technology to be a way for them to keep the citizens connected to the national grid and to bridge the gap between an increasingly independence-seeking energy customer and a main electric grid dependent electricity provider. One of the interviewees illustrates their view on the future end-user scenario in the following quote:

'In the future, Mrs. Hansen can sit in her apartment and tell her TV that she needs to go to the doctor. Then the TV will make sure she has an electric car charged from the carpool waiting for her. And she will have a smart meter in her living room telling her when the electricity prices are low so that she can wash her clothes.'

Representative of utility company

(Translated from Norwegian by authors)

A participant from the utility company in the ZVB case explains that they are currently questioning whether they as an energy provider should play the role in designing the interfaces between the different solutions; mobility, energy use and user behaviour in general. In other words, if they should be involved in the integration of smart technology into buildings, apartments and transport. In the Furuset case, the utility company appears to be more interested in strengthening the role of their district heating system, and wish to influence the legal framework which allows them to require that buildings, old and new, are attached to their energy infrastructure. In the Furuset case, the utility company's strong emphasis on district heating is met through suggestions by city planners to visualize the energy use locally. This is because extensive participatory processes at the beginning of the planning of Furuset raised the need for making the Furuset area more attractive to investors, and to increase local ownership. Further, the goal retrieved from the participatory processes, of reducing traffic through the center of Furuset, has led to the utility company making an agreement with an electric bus company, where the utility company will deliver energy to the local buses. The emphasis on socioeconomic values of district heating is also found in the argumentation of the utility company at Furuset:

'the model that guides the energy label organization today focuses on delivered energy, and it disfavors both electricity and also district heating, because it is delivered, while internally produced energy is favored.... In our view, it is easy to think that either [SEC] is a stand-alone island or it is not. We of course want to use district heat to as large as an extent as possible, from our system, and we think that it is socioeconomically great. We have a large surplus from waste combustion, which we want to use, and of course this influences what type of energy carrier is valued in a community system...let me take an Oslo-example. It is so that in district heating, $60 \%$ is based on surplus energy, energy that wouldn't be used if it wasn't attached to the waste combustion in Oslo. And then we have $10 \%$ of the energy structure attached to sewage pumps in Oslo, which if we had cut that, it would also not have been used. So...we apply services and exploit resources that if not would have been wasted. So, we regard these, as examples of $\mathrm{CO}_{2}$ neutral energy carriers, energy sources[...] We see neighbourhoods as Oslo, we do not see neigbourhood as simply a cluster of dwellings. So if zero emission buildings are stand-alone buildings, neigbourhoods will also include our delivered [grid] thermal energy'.

Representative of utility company

(Translated from Norwegian by authors) 
The municipality city planners on their hand view their main mandate to ensure a 'good city' in terms of good living environments for their citizens. Of energy-related issues, they focus on localization of buildings and placement and are interested in finding ways to increase the use of bikes and walking. They want to see buildings that invite end-users to live sustainably and want to see buildings and communities that inspire people to not use private vehicles. They miss better inclusion of citizens' needs into the SEC plans and in this way support the utility companies' question about increased use of alternative scenarios for SEC planning.

3.3 Which measures may be taken within municipal planning of SECs to help manage the identified challenges and opportunities?

In Bergen, city planners, and climate section staff would like to see utility companies play a more central role in providing innovative solutions for reducing emissions, yet they are finding difficulties in negotiating with utility companies on SEC planning strategies:

'we for example propose that we would like some alternative suggestions on what kind of streetlights we want here... but then the utility company which provides for this [other] area say that they will not do this... [other thing that the new alternatives depend on]'

Representative of climate section (Translated from Norwegian by authors)

The municipalities believe that they can have a clearer influence on energy issues and the overarching emission reduction goals through:

- Increased legal agreements to demand the inclusion of energy issues and utility companies' involvement earlier.

- Tools to help them achieve the right sequence of implementation steps in a community, to ensure that the needs of citizens' well-being and private interests are met. Their main concern is localization that reduces private car traffic and that services such as schools and public meeting places are central also in SEC planning.

- improved in-house competency on energy and clear responsibility on who within the municipality has the mandate to integrate energy planning into work to lower emissions.

Utility companies, however, explain that they think they play a useful role as advisors to the politicians on how the future communities of Bergen and Oslo should be designed in relation to energy use, yet they perceive that the municipalities lack clear visions. This discourse is in line with the negotiation difficulties described in research on the results of liberalization of the utilities in Europe [14, 16, 20].

Moreover, the lack of socio-economic cost-benefit analyses in the current planning tools for SECs makes it difficult for the municipalities to manage the utility companies' influence on the final design. The utility companies agree with the private developers on the fact that it is cost and supply security that drives the decisions of private developers instead of what they refer to as a 'green profile'. Yet, they see the need for the municipalities to present a clearer view of what they want. Finally, utility companies would like to see increased incentives from the side of the municipality to ensure energy renovation of existing buildings. This energy renovation must be viewed in relation to the district heating regulation in 
Norway where municipalities may impose on buildings an obligation to connect to a district heating system within a defined concession area. This obligation has impacted the growth in district heating. Utility companies see that it is relatively easy to regulate newer buildings in this regard, while lowering emissions in the Furuset case optimally will require energy renovation and obligation to connect to the district heating system also for the existing buildings. ZVB is different, as it is planned to be built on an undeveloped area where building renovation isn't an issue. Bergen city planners and climate section would like to see more SEC projects within the densification zone of the city in the future, hence the participants in both municipalities call for tools and incentives that can help them plan and to transform existing buildings, communities and neighbourhoods.

\section{DISCUSSION}

Utility companies in Furuset and ZVB were involved late in the planning process of the two smart energy communities. This shows that the two cases have followed a traditional urban planning process in which planning considers mostly the spatial characteristics of a certain area, which is carried out through zoning plans. Energy planning is then carried out only after these spatial plans are made, and the energy planning is often left to the utility companies (Kuronen et. al., 2010). This is consistent with what is expressed by interviewees involved in the planning of the two case studies; energy planning seems to be a completely separate process taking place only after land-use planning is completed. Previous research has shown that this is how the planning process in Oslo normally is practiced (Resch \& Andresen, 2017). Still, utility companies' influence on priorities in the final SEC design seems to be strong due to their resources competency, and historical connection to the municipality, as well as the lack of business models for renewable energy that suits the Norwegian monopolistic energy market. According to the climate section staff in Bergen and Oslo, earlier inclusion of utility companies in the planning process could result in a better interplay between the main utility providers and renewable energy services within the SEC, as well as more focus on innovative approaches to lower emissions. They perceive that innovative results depend on a better interplay between the traditional utility providers and new ideas for local energy generation and business models.

\subsection{Utility companies' role in definitions and strategies}

In line with sustainable cities research 'Competing conceptions of sustainable cities lead to the development of a range of initiatives, strategies and plans, and the emergence of alternative logics of environmental innovation' [21]. Regarding the view on the meaning of SEC, the utility companies operate with two narratives for urban energy futures:

a. The 'island' of 'Smart Energy Community'. The isolated calculation of a clearly defined area of buildings and infrastructure producing its own energy and seeking independence. This narrative is regarded as a threat to the current conventional grid business model of the major utilities in Norway.

b. The 'all-encompassing' Zero Emission Neighbourhood where participants believe everything 'down to what is eaten for breakfast' is included.

The utility companies relate to these narratives in a pragmatic way, but different in the two cases. Both of the above-mentioned views are presented by the utility companies as research 
ideas that do not take into account costs and benefits, which they in turn can provide. This means that the utility companies fill an important practical function that is invaluable for the municipalities who do not have strong energy competencies in-house. In the Bergen case, which is regarded as belonging to the 'island' thinking, the utility company answers to the foreseen 'threat' of energy independence-seeking customers by proposing that the utility company could offer services within homes which make peoples' energy reality simpler and more convenient.

In the case of Oslo, the utility companies become influencers and argue for the benefit of using the district heating grid, and wishes to expand this infrastructure. In both cases, we see that utility companies move from the outside of the planning process into a role where they seek to keep their market share.

General ideas of what meaningful resource use means to city planners are met by suggestions by utility companies. For example, within the Oslo case, the urban planners seem to have the common view that 'it is good to use what you have'. This narrative is found in how they value the Furuset area and its existing value historically and socially, and their wish to keep this value through an inclusive planning processes. The narrative is then recovered in the ideas by city planners that the ownership feeling of citizens of Furuset will be increased if they can see 'what they have' and visualize energy use and production. The idea that local energy production should be used locally to create ownership matches with the first narrative of 'island' thinking of SECs. This narrative and the view of the citizens of Furuset, as a collective, seem to affect the definitions of 'green' energy.

\subsection{The envisioned future role of utility companies}

Participants contributions indicating that utility companies see the self-sufficient SEC idea as a possible threat to their current business model, and their interest in discussing new ways to make ZEN and SEC thinking feasible by matching their definitions and strategies with their own services. From this, it becomes evident that utility companies are aware of their need to rethink their strategies in relation to urban planning. At the same time, the different narratives in the two cases also show that the utility companies do not have a set definition space to decide what a Smart Energy Community should achieve and to discuss alternative options regarding energy provision. Instead, they show that their experience strengthen their already prominent advisory role to make the energy infrastructure feasible and cost effective, and that will make sure they keep their role in the energy planning in the future. They also see the current trend of customer energy independency as a threat and that the involvement with municipal planning can be a way for them to manage this threat. The lack of discussion on whether the grid electricity and municipal waste heat are emission-free, together with the lack of discussion on how to reduce energy through SEC design, is symptomatic. This exemplifies how utility companies are involved in SEC planning, yet it also shows the need for competency within the municipalities on integrated energy planning and its link to emission reduction. Regarding the future role of utility companies in Norwegian municipalities, with new energy technologies on the rise, the utility companies who are providing centralized energy solutions may feel the pressure from start-ups as well as from individual consumers deploying decentralized energy solutions such as solar systems and heat pumps. This is seen as a clear threat to their business model, and the utility companies have already initiated plans to take an edge in this arising decentralized energy market according to utility participants. 


\subsection{Improving municipalities' ability to manage the development of SECs}

There is no clear and common definition of what zero emission means on a community scale. Instead, the stakeholders compose their own understanding as the project progresses, and adjust strategic measures to what the current legal framework allows. City planners lament that this legal framework currently is limited to the design of individual buildings, and they wish for legal frameworks that can assist them in demanding energy related issues to be included earlier.

\section{CONCLUSIONS AND FURTHER WORK}

Based on the two cases we see that a lack of agreement on what a SEC design should include and how it should be planned leads to the involved stakeholders making decisions along the way based on logics constructed by a composition of their individual ideals. City planners focus on fulfilling what they perceive as the citizens' needs, while the utility company focuses on their future business model opportunities and how to apply their experience in a beneficial way. The data analysis further showed an overall image where the utility companies' perspectives on future roles and the perceived threat of local energy production had hued their input to the definition and strategies within the SEC planning. It further shows that in lack of clear definitions, different forms of collaboration between municipality planners and the utility companies had shaped somewhat different strategies for the two projects.

We see that in the current planning of the two smart energy communities, utility companies become involved late in the planning process. Despite their late arrival to the process, utility companies quickly take a leading role in deciding the definition space of what a smart energy community is within that project, and in the municipality planning practice in general. Once the utility companies are on board, the view of what the SEC should or could look like is adjusted, for example from the vision of 'zero emission resources' towards the vision of 'exploiting locally available resources' and optimal use of the utility companies' services.

In our two studied cases of SEC planning processes, it is interesting to see to which extent municipalities look to the major utility companies to understand how to realize the final SEC plans. We see that the utility companies add the feasibility aspects and their prioritized agendas of cost/benefit and energy supply security to the discussion. They further contribute to strategic thinking based on their envisioned future role. Taking this lead role is not due to malintention from the side of the utility companies, but rather it may be a result of the historically monopolized Norwegian energy market. Still, it is an argument for finding SEC planning approaches that manage to broaden the scope to include more innovative and alternative energy scenarios. Parts of the reason that utility companies influence the definitions is also that stakeholders perceive that ZEN and SEC thinking is 'island' thinking and that this view is impractical in the Norwegian context where connection to the grid is an ideal and the idea of 'supply security' is strong. This shows the need for research that exemplifies integrated design, which also works aligned with cost/benefit frameworks and that can also work in areas which combine existing and new buildings and infrastructure. The findings illustrate a clear need for definitions and strategies that can strengthen the role that municipalities must take to manage building, community, and neighbourhood planning towards a zero-emission vision.

Both Oslo and Bergen have ambitious goals for reduction of greenhouse gas emissions in the years to come. Emission accounting is, however, not straightforward. In the same way that the definitions of SEC and ZEN are unclear, so are the definitions of the municipalities' emission targets. The energy use in urban areas consists of the direct consumption of energy for the operation of industries, infrastructure, buildings, and transportation of people and 
goods, as well as the indirect (embodied) energy in materials of the built environment and the consumed goods. It is not clear which emissions should, and should not, be attributed to the municipality. There is a need for further work on developing calculation methods and tools for effective accounting of these issues in the planning of SEC.

In sum, our findings support the need for academia to play a guiding role in the municipalities work to plan smart energy communities and zero emission neighbourhoods. Further work in the PISEC project therefore include developing tools and strategies for integrating energy planning based on the two cases; and to test them in the planning of Smart Energy Communities in Norway.

\section{ACKNOWLEDGMENTS}

The Norwegian Research Council supported this work. We also gratefully acknowledge the participants in the interviews.

\section{REFERENCES}

[1] Pan, W., System boundaries of zero carbon buildings. Renewable and Sustainable Energy Reviews, 37, pp. 424-434, 2017. https://doi.org/10.1016/j.rser.2014.05.015

[2] Kristjansdottir, T.F., Heeren, N., Andresen, I. \& Bratteb $\varnothing$, H., Comparative emission analysis of low-energy and zero-emission buildings. Building Research \& Information, $1-16,2017$. https://doi.org/10.1080/09613218.2017.1305690

[3] Lindberg, K.B., Doorman, G., Fischer, D., Korpås, M., Ånestad, A. \& Sartori, I., Methodology for optimal energy system design of Zero Energy Buildings using mixedinteger linear programming. Energy and Buildings, 127, pp. 194-205, 2016. https://doi.org/10.1016/j.enbuild.2016.05.039

[4] Byråd for Klima kon. KLIMA- OG ENERGIHANDLINGSPLAN FOR BERGEN, 2016.

[5] Climate CoOAf. Climate and Energy Strategy for Oslo; Adopted by the City Council in Oslo 22.06.2016 (Proposition 195/16). 2016.

[6] Graabak, I., Bakken, B.H. \& Feilberg, N., Zero emission building and conversion factors between electricity consumption and emissions of greenhouse gases in a long term perspective. Environmental and Climate Technologies, 13(1), pp. 12-19, 2014. https://doi.org/10.2478/rtuect-2014-0002

[7] Sartori, I., Dokka, T. \& Andresen, I., Proposal of a Norwegian ZEB definition: assessing the implications for design. Journal of Green Building, 6(3), pp. 133-150, 2011. https://doi.org/10.3992/jgb.6.3.133

[8] Bulkeley, H. \& Betsill, M., Rethinking sustainable cities: multilevel governance and the'urban' politics of climate change. Environmental Politics, 14(1), pp. 42-63, 2005. https://doi.org/10.1080/0964401042000310178

[9] Davoudi, S., Shaw, K., Haider, L.J., Quinlan, A.E., Peterson, G.D., Wilkinson, C., Fünfgeld, H., McEvoy, D., Porter, L. \& Davoudi, S., Resilience: a bridging concept or a dead end?"Reframing" resilience: challenges for planning theory and practice interacting traps: resilience assessment of a pasture management system in Northern Afghanistan urban resilience: what does it mean in planning practice? Resilience as a useful concept for climate change adaptation? The politics of resilience for planning: a cautionary note: edited by Simin Davoudi and Libby Porter. Planning Theory \& Practice, 13(2), pp. 299-333, 2012.

https://doi.org/10.1080/14649357.2012.677124 
[10] Henry, C., Matheu, M. \& Jeunemaitre, A., Regulation of network utilities: the European experience, Oxford University Press, New York, NY, 2001.

[11] Newberry, D.M., Privatization, restructuring, and regulation of network utilities. MIT Press, Cambridge, MA, 2002.

[12] Monstadt, J., Urban governance and the transition of energy systems: Institutional change and shifting energy and climate policies in Berlin. International Journal of Urban and Regional Research, 31(2), pp. 326-343, 2007. https://doi.org/10.1111/j.1468-2427.2007.00725.x

[13] Serrallés, R.J., Electric energy restructuring in the European Union: integration, subsidiarity and the challenge of harmonization. Energy Policy, 34(16), pp. 2542-2551, 2006.

https://doi.org/10.1016/j.enpol.2004.08.041

[14] Eising, R., Policy learning in embedded negotiations: explaining EU electricity liberalization. International Organization, 56(1), pp. 85-120, 2002. https://doi.org/10.1162/002081802753485142

[15] Marius Lorentzen LS, Ertesvåg F. Rett til slaktebenken: Oslo kommune vil kjøpe tilbake og dele opp Hafslund. e24no. 2017 26.04.2017.

[16] Mirakyan, A. \& De Guio, R., Integrated energy planning in cities and territories: a review of methods and tools. Renewable and Sustainable Energy Reviews, 22, pp. 289-297, 2013. https://doi.org/10.1016/j.rser.2013.01.033

[17] Bagnoli, A., Beyond the standard interview: the use of graphic elicitation and arts-based methods. Qualitative Research, 9(5), pp. 547-570, 2009. https://doi.org/10.1177/1468794109343625

[18] Crilly, N., Blackwell, A.F. \& Clarkson, P.J., Graphic elicitation: using research diagrams as interview stimuli. Qualitative Research, 6(3), pp. 341-366, 2006. https://doi.org/10.1177/1468794106065007

[19] Biernacki, P. \& Waldorf, D., Snowball sampling: Problems and techniques of chain referral sampling. Sociological Methods \& Research, 10(2), pp. 141-163, 1981. https://doi.org/10.1177/004912418101000205

[20] Gabillet, P., Energy supply and urban planning projects: Analysing tensions around district heating provision in a French eco-district. Energy Policy, 78, pp. 189-197, 2015. https://doi.org/10.1016/j.enpol.2014.11.006

[21] Guy, S. \& Marvin, S., Understanding sustainable cities: competing urban futures. European Urban and Regional Studies, 6(3), pp. 268-275, 1999. https://doi.org/10.1177/096977649900600307 